\title{
Decisions Relating to Cardiopulmonary Resuscitation: commentary 2: Some concerns
}

Steven Luttrell Consultant geriatrician and general physician, Camden and Islington Community Health Services NHS Trust, London

In March of this year the British Medical Association (BMA), the Resuscitation Council (UK) and the Royal College of Nursing (RCN) published guidelines outlining the legal and ethical standards for decision making in relation to cardiopulmonary resuscitation (CPR). ${ }^{1}$ The guidance follows a year of increasing public awareness and concern about the issue and builds upon joint guidance issued by these institutions in June 1999 .

In April 2000 Age Concern issued a press release stating that "some doctors are ignoring national guidelines on the resuscitation of older people" and indicating that they had information on cases that had come to light in their campaign against age discrimination. Age Concern went on to say that older people have found "not for resuscitation" recorded in their medical notes without their agreement or knowledge.

During the same month Professor Shah Ebrahim wrote a leader in the British Medical fournal stating that doctors regularly issue "do not resuscitate" orders for patients without their knowledge. ${ }^{2} \mathrm{He}$ claimed that black people, alcohol mis-users, non-English speakers and those with HIV are more likely to get a "do not resuscitate" order, suggesting that prejudice is influencing medical decisions.

This combination of events was followed by intense press and media interest in the way in which decisions were being made about cardiopulmonary resuscitation. Such was the level of concern that a health service circular was issued to all National Health Service (NHS) trust chief executives in September 2000 asking that appropriate resuscitation policies be in place which respect patients' rights, are understood by all relevant staff and are subject to appropriate audit and monitoring. ${ }^{3}$

Previous guidance issued by the BMA, the Resuscitation Council and the Royal College of Nursing in 1999 was four pages long and covered issues such as when it was appropriate to consider a do-not-resuscitate order, the role of senior doctors in decision making and the need for sensitive discussion with patients. ${ }^{4}$ The most recent guidance by them is five times as long and covers the various ethical and legal issues relating to decision making in greater depth. But does it address the particular issues that underpin the public concern?

\section{Transparency and involvement}

The guidance gives considerable weight to the need to provide information and discussion. It states that written information about resuscitation policies should be readily available to all patients and to those others who are close to the patient.

It indicates that patients have an ethical and legal right to be involved in decisions that relate to them. It reinforces the message given in previous guidance that sensitive discussion should take place if a patient is at foreseeable risk of cardiopulmonary resuscitation or is terminally ill. Indeed, although not explicitly stated, there is an implicit message that an offer of discussion should be made to all mentally competent patients for whom a "do not attempt resuscitation" order is made. This emphasis on discussion is to be welcomed and very much in line with the results of research that indicates that patients want to be included in discussions about CPR. In Morgan's study of 100 alert patients with a mean age of 80 and the wishes of their next of kin it was found that $89 \%$ of patients thought decisions about CPR should be discussed with them and $88 \%$ of relatives thought such decisions should be discussed with them. Interestingly $34 \%$ of patients felt that their relatives should not be involved and $37 \%$ of relatives felt that patients should not be involved. ${ }^{5}$

Although the guidance indicates that doctors should sensitively portray to patients the inherent uncertainty in this type of clinical decision and that it is problematic that many patients have unrealistic expectations about the potential benefits of CPR, it does not go into detail on how doctors and other health staff might become better at discussing these issues with their patients. This is certainly an area of work that needs to be addressed at a local level. Doctors will have to make time for discussions and there are obvious skills and training implications. 
The guidance makes it clear that people close to a mentally incapable patient should be involved in decision making in order to reflect the patient's views and wishes. Clearly, to make health decisions in the best interests of mentally incapable patients, the clinician should take into account the previous wishes and feelings of the person. This very much reflects the view of the Law Commission in its $1995^{6}$ report and that of the government in its report Making Decisions. ${ }^{7}$ It is arguable, however, that the guidance does not go far enough to clarify the role of relatives and close friends. It gives the impression that their part is merely to reflect the views and wishes of the person. Surely, their views as to what is in the best interests of the patient are also relevant and should be taken into consideration.

One of the more controversial situations highlighted in the debate on decision making occurs when the doctor states that CPR is futile whilst the patient indicates that he/she still wants to give it a go. The guidance steers a middle way on this issue, making it clear that although doctors cannot be required to give treatment contrary to their clinical judgment, they should respect the wishes of a patient to receive a treatment which carries only a very small chance of success. This approach would appear to answer many of the concerns raised by both the public and professionals. It is surely right that doctors are not required to undertake interventions that have no chance of success. On the other hand, where there is a small chance of success and the patient is aware of this, and the risks, and willing to give it a go, there seems no justifiable reason for not attempting CPR.

\section{Making the right decision}

The public's concern is that some people, particularly those who are older and for whom attempted resuscitation is appropriate, are being denied CPR. The guidance, like its 1999 predecessor, makes it clear that there are situations where doctors can justifiably not start CPR namely (i) where CPR will not start the heart; (ii) where there is no benefit in restarting the heart and breathing, and (iii) where the expected benefit is outweighed by the burdens. It is scenarios (ii) and (iii) that precipitate ethical debate. They call for a judgment on what constitutes benefit and how this should be weighed against burden. It is in these situations that it is vital to involve the patient, and where appropriate, relatives or others close to the patient, in decision making. It is in these situations that it is particularly important that decisions are seen to be made in a fair and transparent manner. It is no longer acceptable for the doctor to be the only or final arbiter on what constitutes benefit to his/her patients.

\section{Conclusion}

The latest guidance from the BMA, the Resuscitation Council and the RCN substantially addresses the public's concerns that decisions about cardiopulmonary resuscitation should be made in a fair and transparent manner. National Health Service trusts are now faced with the task of ensuring that they have local policies in place and that they monitor performance against these. Patients, their relatives and those close to them need to be aware of their rights to be involved in discussions. Health professions need to have the right knowledge, attitude, skills and time for discussion. It is only when all these changes are in place that we can be confident that the system will improve.

Steven Luttrell is a Consultant Geriatrician and General Physician with the Camden and Islington Community Health Services NHS Trust, London.

\section{References}

1 British Medical Association, Resuscitation Council (UK), Royal College of Nursing. Decisions relating to cardiopulmonary resuscitation: a joint statement from the British Medical College of Nursing. London: British Medical Association, 2001. College of Nursing. London: British Medical

Fournal of Medical Ethics 2001;27:312-18.
Ebrahim S. Do not resuscitate decisions: flogging dead horses 2 Ebrahim S. Do not resuscitate decisions: flogging dead horses elderly people without discussion. British Medical fournal 2000;320:1115-16.

3 NHS Executive. Resuscitation policy (HSC 2000/028). London: Department of Health, September 2000. Scottish Executive Health Department. Resuscitation policy (HDL (2000) 22). Edinburgh: Scottish Executive, November 2000. www.doh.gov.uk/coinh.htm.

4 British Medical Association, Resuscitation Council (UK), Royal College of Nursing. Decisions relating to cardiopulmonary resuscitation. London: British Medical Association, 1999.

5 Morgan R, King D, Prajapati C, Rowe J. Views of elderly patients and their relatives on cardiopulmonary resuscitation. pritish Medical fournal 1994;308:1677-8.

6 Law Commission. Mental incapacity. law com No 231. London: HMSO, 1995.

7 Lord Chancellor's Department. Making decisions: the government's proposals for making decisions on behalf of mentally incapacitated adults. London: The Stationery Office, October 1999. Available on www.open.gov.uk/lcd. 